\title{
Distribution and Frequency of Fusarium Species Associated with Soybean Roots in lowa
}

\author{
M. M. Díaz Arias, G. P. Munkvold, M. L. Ellis, and L. F. S. Leandro, Department of Plant Pathology and Microbiology, Iowa State
} University, Ames \begin{abstract}
bean roots in Iowa. Plant Dis. 97:1557-1562.
A 3-year survey was conducted in Iowa to characterize the distribution and frequency of species of Fusarium associated with soybean roots. Ten plants were collected from each of 40 to 57 fields each year at V2 to V5 and R3 to R4 soybean growth stages. Fusarium colonies were isolated from symptomatic and symptomless roots and identified to species based on cultural and morphological characteristics. Species identification was confirmed by amplification and sequencing of the translation elongation factor $(\mathrm{EF} 1-\alpha)$ gene. Fifteen species were identified; Fusarium oxysporum was isolated most frequently, accounting for more than $30 \%$ of all isolates. F. acuminatum, $F$. graminearum, and $F$. solani were also among the most frequent and widespread species.
\end{abstract}

Abstract

Díaz Arias, M. M., Munkvold, G. P., Ellis, M. L., and Leandro, L. F. S. 2013. Distribution and frequency of Fusarium species associated with soy-

Eleven other species were recovered from few fields, accounting for less than $10 \%$ of all isolates in a given year. No consistent trends were observed in geographic distribution of species. Variability in species frequency was found between soybean growth stages. Fusarium oxysporum was recovered at higher frequency during vegetative stages (40\%) than reproductive stages $(22 \%)$. Conversely, species such as $F$. acuminatum, $F$. graminearum, and $F$. solani were recovered more often from reproductive-stage plants. No significant differences in species composition were observed among fields differing in tillage practices and row spacing.
Fungi in the genus Fusarium cause several diseases of soybean (Glycine $\max$ (L.) Merr.), including Fusarium wilt, caused by Fusarium oxysporum Schltdl. (2); sudden death syndrome (SDS), caused in North America by F. virguliforme O'Donnell \& T. Aoki (1); as well as seed and seedling diseases and root rot, caused by numerous species $(7,28,33,37)$. Fusarium root rot is a common and widespread disease in the United States (40). At least 19 Fusarium spp. have been isolated from soybean roots in different soybean production areas $(4,5,10,23,24,28,32)$. Previous studies have demonstrated that $F$. oxysporum and $F$. solani are generally the most common species in soybean tissues and the main causal agents of soybean root rot in the United States $(9,13,24,28)$ and other countries $(3,20,41)$. Affected plants may exhibit poor or slow emergence and root symptoms, including dark brown lesions, especially in the lower portion of the root system, or decay of the entire taproot (28).

Several studies on occurrence, distribution, pathogenicity, and cultivar resistance have been conducted for $F$. oxysporum and $F$. solani $(13,14,22,29)$ but there is limited work on the other Fusarium spp. isolated from soybean roots $(4,9,24)$. These reports as well as field observations indicate that colonization of soybean roots by several of these species is common; however, there is very limited information about their pathogenicity on soybean and their impacts on root health and yield.

Fusarium root rot was first reported as a problem in soybean in Iowa in 1953 by Dunleavy (30). The disease was initially attributed to $F$. orthoceras Appel \& Wollenw. but later it was documented that $F$. oxysporum was the predominant fungus isolated from symptomatic soybean roots $(14,30)$. Several other Fusarium spp. have

Corresponding author: L. F. S. Leandro, E-mail: lleandro@iastate.edu

* The $\boldsymbol{e}$-Xtra logo stands for "electronic extra" and indicates that two supplementary figures and one supplementary table are available online.

Accepted for publication 5 June 2013.

http://dx.doi.org/10.1094/PDIS-11-12-1059-RE

(C) 2013 The American Phytopathological Society been consistently isolated from soybean plants in Iowa fields. Nyvall (30), who conducted a 3-year study, isolated Fusarium spp. from pods, stems, and roots from soybean plants collected in nine fields in central and north Iowa. In this study, F. oxysporum was the predominant colonizer of roots and soil, followed by $F$. solani. Another important soybean root rot pathogen in Iowa is $F$. virguliforme, the cause of SDS, and various studies have been done on the biology, epidemiology, and cultivar resistance for this disease $(16,27)$.

Although Fusarium root rot has long been known as a common soybean disease, the importance of this disease to Iowa soybean production in not fully understood. In addition, there is a lack of information about the species involved and their abundance and geographical distribution around the state. Therefore, the objectives of the present study were to (i) characterize the diversity and frequency of Fusarium spp. associated with soybean roots in Iowa and (ii) determine the geographic distribution of Fusarium spp. in Iowa during vegetative and reproductive stages of soybean growth.

\section{Materials and Methods}

Sample collection. Soybean roots were collected during the 2007, 2008, and 2009 growing seasons across the nine Iowa crop reporting districts (Fig. 1). In collaboration with 12 Iowa State University extension specialists, 142 soybean fields from 98 Iowa counties were surveyed over the 3 -year period (Fig. 1). All the fields sampled had corn as the previous crop, with the exception of three locations. Ten plants with as much of the root system as possible were collected arbitrarily from each field at both vegetative (V2 to V5) and reproductive (R2 to R4) growth stages (18); plants were dug and soil was gently shaken from roots before plants were placed in plastic bags. Samples were shipped overnight to the Iowa State University Plant \& Insect Diagnostic Clinic or The Seed Science Center and stored at $4{ }^{\circ} \mathrm{C}$ until processed. Some fields were sampled only at one growth stage and some counties were sampled in more than 1 year. In total, 101 samples was collected from 55 fields in 50 counties in 2007, 77 samples from 40 fields in 40 counties in 2008, and 84 samples from 47 fields in 40 counties in 2009 (Fig. 1). In each field, sampling date, location (geographic coordinates), and soybean growth stage were documented. Row spacing $(19.1,38.1$, and $76.2 \mathrm{~cm})$ and tillage type (conventional 
till, no till, and reduced tillage) were also recorded in order to determine possible differences in species frequency in relation to crop production practices. For each year, statewide average air temperature and precipitation from May to July were obtained from Iowa Environmental Mesonet, Department of Agronomy, Iowa State University (http://mesonet.agron.iastate.edu/climodat/).

Isolation and identification of Fusarium spp. Roots were rinsed under running tap water for $10 \mathrm{~min}$ to remove soil and debris from the field. Fungi were isolated from roots by arbitrarily excising two $1-\mathrm{cm}$-long root pieces from each plant, one from the taproot and one from the lateral root tissue. Root pieces were surface disinfected in $0.5 \% \mathrm{NaOCl}$ for $2 \mathrm{~min}$, rinsed three times in sterile distilled water, and blotted dry. Root pieces were embedded in antibiotic-amended Nash Snyder medium (per liter: $15 \mathrm{~g}$ of peptone, $1 \mathrm{~g}$ of $\mathrm{KH}_{2} \mathrm{PO}_{4}, 0.5 \mathrm{~g}$ of $\mathrm{MgSO}_{4} \cdot 7 \mathrm{H}_{2} \mathrm{O}, 20 \mathrm{~g}$ of agar, $0.75 \mathrm{~g}$ of pentachloronitrobenzene (PCNB), streptomycin sulfate solution at $33 \mathrm{mg} / \mathrm{ml}$, and neomycin sulfate solution at $40 \mathrm{mg} / \mathrm{ml}$ ) and incubated at room temperature $\left(25 \pm 2{ }^{\circ} \mathrm{C}\right)$ for 7 days under fluorescent light. Numbers of root pieces with putative Fusarium colonies were recorded for each sample. Colonies were transferred into $1.5-\mathrm{ml}$ centrifuge tubes containing potato dextrose broth (PDB) by removing a small piece of mycelium from the colony margin, maintained on a rotary shaker at $200 \mathrm{rpm}$ for 3 to 5 days to allow colony growth, and then stored at $4{ }^{\circ} \mathrm{C}$ for future species identification.

From each set of 10 plants sampled per field, 1 to 20 putative Fusarium isolates were recovered. In total, 2,193 isolates (793 isolations in 2007, 588 in 2008, and 812 in 2009) were collected. For identification to species level, 1 to 15 isolates were selected arbitrarily from within each field sample, for a total of 1,640 isolates. Each isolate was transferred from PDB to carnation leaf agar (CLA) (25) amended with $\mathrm{KCl}$ (15 g of agar and $6 \mathrm{~g}$ of $\mathrm{KCl}$ per liter) and antibiotic-amended potato dextrose agar (PDA) (streptomycin sulfate solution at $33 \mathrm{mg} / \mathrm{ml}$, neomycin sulfate solution at $40 \mathrm{mg} / \mathrm{ml}$, and $39 \mathrm{~g}$ of PDA per liter), and cultures were incubated for 7 to 20 days at room temperature under fluorescent light. Each of the 1,640 isolates was examined microscopically and identified to species according to the system of Leslie and Summerell (25). Species were identified based on the most distinctive morphological characteristics, including macroconidia and microconidia, production of mesoconidia (e.g., F. semitectum), conidial arrangements (singly, false heads, and chains), nature of the conidiogenous cells (monophialides [e.g., F. oxysporum] or polyphialides [e.g., $F$. proliferatum]), conidiophore length (e.g $F$. solani versus $F$. oxysporum), formation and arrangement of chlamydospores (e.g. $F$.

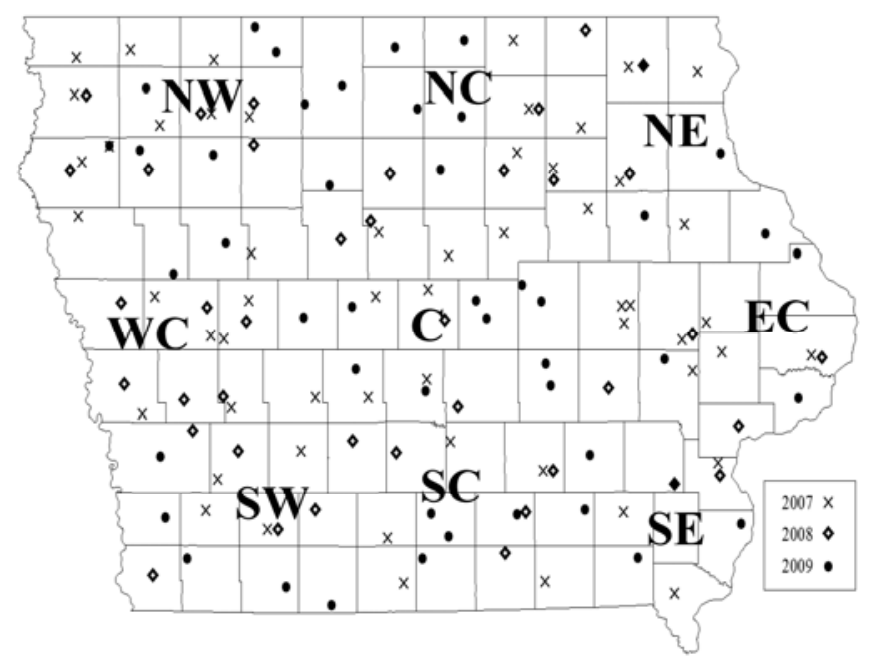

Fig. 1. Location of 142 soybean fields surveyed in 98 lowa counties during the 2007, 2008, and 2009 growing seasons across the nine lowa crop reporting districts: Northwest (NW), North Central (NC), Northeast (NE), West Central (WC), Central (C), East Central (EC), Southwest (SW), South Central (SC), and Southeast (SE). equiseti), production and color of sporodochia on CLA, and colony appearance and pigment formation on PDA (Supplementary Figure 1). Of the 1,640 isolates identified, 1,254 were species of Fusarium based on cultural and morphological characteristics.

Species identities were confirmed for a subset of 170 isolates by amplification and sequencing of the elongation factor 1- $\alpha(E F 1-\alpha)$ gene region. The isolates were selected to represent all the distinguishable and unknown morphological groups that were observed. Single-spore cultures were obtained for each of the 170 isolates used for molecular identification. All isolates were grown on PDA at room temperature for 7 days. The mycelia were harvested, 50 to $100 \mathrm{mg}$ of mycelia was placed into a $1.5-\mathrm{ml}$ centrifuge tube, and then each sample was lyophilized for 2 days and immediately crushed with a sterile pestle in the tube. Genomic DNA was extracted using the cetyltrimethylammonium bromide procedure (19). DNA was quantified using a spectrophotometer and then stored at $-20^{\circ} \mathrm{C}$ until processed. Primers pair used for amplification and sequencing were efl/ef2 (5'ATGGGTAAGGAGGACAAGAC$3^{\prime} / 5^{\prime}$ GGAAGTACCAGTGATCATGTT-3') and efl/ef22 (5'-AGG AACCCTTACCGAGCTC-3'), respectively $(15,31)$. Polymerase chain reactions (PCRs) were conducted in 20- $\mu$ l volumes. Each reaction tube contained approximately $1 \mu \mathrm{l}$ of a $1-\mathrm{ng} / \mu \mathrm{l}$ DNA template, $3.2 \mu \mathrm{l}$ of $10 \times$ Titanium Taq buffer $\left(35 \mathrm{mM} \mathrm{MgCl}_{2}\right), 9.7 \mu \mathrm{l}$ of sterile distilled water, $2 \mu \mathrm{l}$ of $2 \mathrm{mM}$ dNTPs, $2 \mu \mathrm{l}$ each of forward and reverse primers $(2.5 \mu \mathrm{M})$, and $0.1 \mu \mathrm{l}$ of DNA Taq polymerase (Titanium $T a q$ ). The thermal cycling parameters were initial denaturation at $94^{\circ} \mathrm{C}$ for $1 \mathrm{~min}$ followed by 31 cycles consisting of denaturation at $94^{\circ} \mathrm{C}$ for $30 \mathrm{~s}$, annealing at $53^{\circ} \mathrm{C}$ for $45 \mathrm{~s}$, and extension at $72^{\circ} \mathrm{C}$ for $1 \mathrm{~min}$. A final extension at $72^{\circ} \mathrm{C}$ for 5 min was done at the end of the amplification. PCR products were purified adding $2 \mu \mathrm{l}$ of ExoSAP-IT reagent (Affymetrix Inc.) in $5 \mu \mathrm{l}$ of PCR. PCR products were sequenced at the Iowa State University DNA and Sequencing Facility. DNA sequences were trimmed to 400 to 500 bp using CodonCode Aligner 4.1.1 (CodonCode Corp.). Sequences were submitted for BLAST searches for comparison to known DNA sequences in the National Center for Biotechnology Information (NCBI) (http://ncbi.nlm.nih.gov) and the FUSARIUM-ID/FUNCBS databases in Fusarium MLST (http://www.cbs knaw.nl/Fusarium). Sequences were also compared with reference strains from The Fusarium Laboratory Manual (25) using BLASTn from NCBI (http://ncbi.nlm.nih.gov). The accession numbers for the reference strains and the percent identity of the isolates to those strains are listed in Supplementary Table 1.

Data analysis. For each Fusarium sp., relative frequency and incidence were calculated using the total number of Fusarium isolates and root pieces, respectively, from all fields sampled in a given year. The relative frequency $(F)$ of Fusarium spp. was evaluated using the formula $F=100 \times(n / N)$, in which $n=$ the number of isolates of each species and $N=$ the total number of isolates of all species (34). Incidence of each species was defined as the percentage of all root pieces which yielded that species (26), and was estimated as $I_{S}=100 \times\left(r_{s} / r_{i}\right) \times r_{a} / R$, in which $r_{s}=$ number of root pieces yielding a species, $r_{i}=$ number of root pieces selected for identification, $r_{a}=$ number of root pieces yielding any isolate, and $R=$ total number of root pieces sampled. Prevalence of Fusarium spp. was calculated at the state level, using both field and county as sampling units, by dividing total number of fields or counties in which each Fusarium spp. was present by total number of fields or counties sampled around the state. In addition, Fusarium spp. prevalence was calculated at the district level as the total number of fields in which each Fusarium spp. was present $(\times 100)$ divided by the total number of fields sampled per district.

Frequencies of isolation were compared for the overall data set to test for differences among species, and between crop growth stages, tillage practices, row spacing, and root type (lateral versus taproot). Analyses of variance were conducted using the general linear model procedure (PROC GLIMMIX) of SAS (version 9.2, SAS Institute) using year as replication (random factor). Differences among means were compared using the Tukey-Kramer test and considered significantly different if $P \leq 0.05$. Incidence and 
prevalence data were analyzed for the overall data set, as well as for tillage and row spacing, using the same model as above.

\section{Results}

Fifteen species were identified, including $F$. acuminatum, $F$. armeniacum, $F$. avenaceum, $F$. equiseti, $F$. graminearum, $F$. oxysporum, $F$. poae, $F$. proliferatum, $F$. semitectum, $F$. solani, $F$. sporotrichioides, $F$. subglutinans, $F$. tricinctum, $F$. verticillioides, and F. virguliforme (Fig. 2). Morphological characteristics such as mycelium appearance, growth rate, pigment, and spodorochia formation varied among isolates within a species, particularly for $F$. armeniacum, $F$. semitectum, $F$. oxysporum, and $F$. solani. Strains belonging to the $F$. oxysporum complex showed the widest variation in culture morphology on PDA.

Frequency of isolation of Fusarium spp. Mean frequency of isolation averaged over years (data not shown) varied among Fusarium spp. $(P<0.0001)$. Frequency of isolation of $F$. oxysporum, $F$. acuminatum, and $F$. solani was greater $(P<0.0001)$ than all the other species. $F$. oxysporum showed significantly higher frequency $(32 \%)$ than all other species, except $F$. acuminatum $(23.9 \%)$. Frequency of $F$. solani was $21.5 \%$ and did not differ from $F$. acuminatum but did differ from all other species which were isolated with a frequency of $8 \%$ or lower. There were no differences in frequency among the remaining species.

The main trends observed in the data plotted per year (Fig. 2) were similar to those observed for data combined over years. $F$. oxysporum was the most frequently recovered species, followed by $F$. acuminatum and $F$. solani, each ranging from 12 to $37 \%$ of the isolates (Fig. 2). Other species such as F. graminearum, $F$. proliferatum, and $F$. sporotrichioides represented 1 to $12 \%$ of the isolates. Remaining species such as F. armeniacum, F. avenaceum, F. equi-

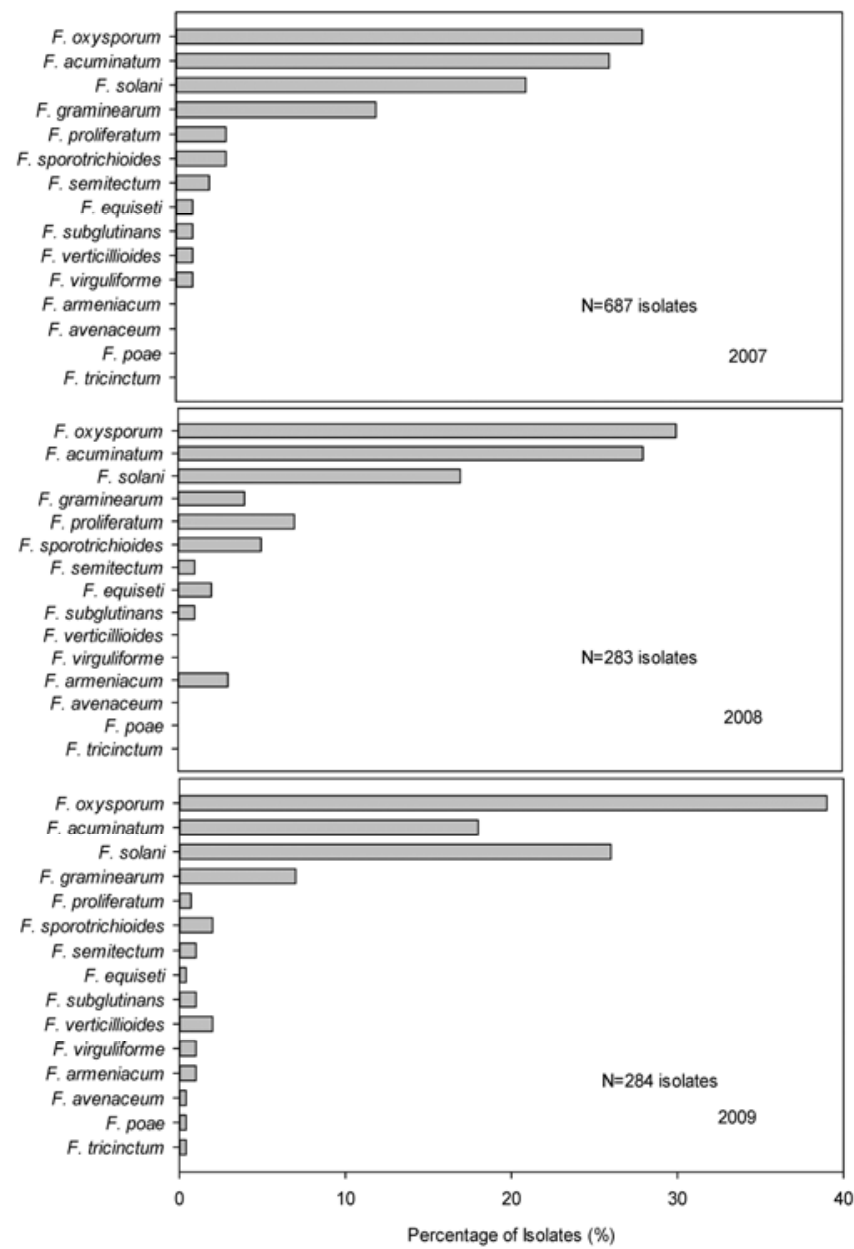

Fig. 2. Frequency of isolation (\%) of Fusarium spp. from soybean roots in lowa in 2007, 2008, and 2009. seti, F. semitectum, F. subglutinans, F. poae, F. tricinctum F. verticillioides, and $F$. virguliforme were less frequent $(<1$ to $3 \%$ of isolates) (Fig. 2). For example, in 2007 and 2008, F. oxysporum was the most frequently isolated ( 28 and $30 \%$, respectively), followed by $F$. acuminatum (26 and $28 \%$, respectively) whereas, in 2009 , the most frequently isolated species were $F$. oxysporum (37\%) and $F$. solani $(27 \%)$. Frequency of isolation of $F$. graminearum was similar in 2007 (12\%) and 2009 (8\%); however, in 2008, a low percentage (4\%) of isolates was recovered for this species (Fig. 2).

Soybean growth stage did not have a significant effect on frequency of isolation of Fusarium spp., in data combined over years, and there was no significant interaction between growth stage and species. When analyzed for each species separately, growth stage had a significant effect on $F$. acuminatum, with a higher $(P=$ $0.027)$ frequency observed at reproductive stages $(29.6 \%)$ compared with vegetative stages (19.3\%) (Fig. 3). No significant differences in relative frequency were found between growth stages for any of the other species (Fig. 3). Although F. oxysporum frequency did not differ significantly between growth stages, the trend for higher frequency at vegetative growth stages compared with reproductive growth stages was present each year (30 versus $26 \%$ in 2007, 40 versus $17 \%$ in 2008, and 54 versus $27 \%$ in 2009 for vegetative and reproductive stages, respectively). The species $F$. avenaceum and $F$. poae were only recovered in reproductive stages, whereas $F$. tricinctum and $F$. virguliforme were only recovered at vegetative stages.

Row spacing did not have a significant effect on relative frequency averaged over all species or when analyzed for each species separately. For example, mean frequency of isolation of $F$. acuminatum was 14,15 , and $21 \%$ for fields with row spacing less than 19,38 , and $76 \mathrm{~cm}$, respectively, and frequency of $F$. oxysporum varied from 22 and $26 \%$ between row spacing treatments. There were also no significant differences between tillage practices in the frequency of overall Fusarium spp. or each species individually. For example, frequency of $F$. acuminatum was 14.4, 21.9 , and $20.5 \%$ for no-till, reduced till, and conventional till, respectively, and varied from 18 to $25 \%$ for $F$. oxysporum and 11 to $18 \%$ for $F$. solani. The type of root piece (tap or lateral) from which isolations were made had no significant effect on frequency of Fusarium spp.

Fusarium spp. incidence and prevalence. Significant differences among species were found for mean incidence $(P<0.0001)$, prevalence at the county level $(P<0.0001)$, and prevalence at the field level $(P=0.003)$ when averaged over years. $F$. oxysporum, $F$.

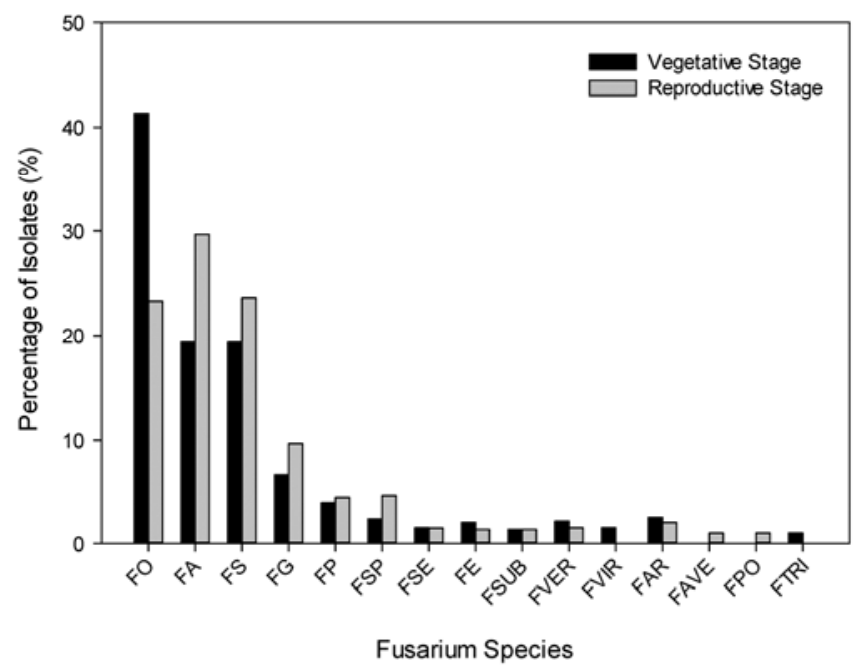

Fig. 3. Frequency (\%) of isolation of Fusarium spp. recovered from soybean roots at two plant stages, V2 to V5 and R2 to R4, from 2007 to 2009. Fusarium oxysporum (FO), F. acuminatum (FA), F. solani (FS), F. graminearum (FG), F. proliferatum (FP), F. sporotrichioides (FSP), F. semitectum (FSE), F. equiseti (FE), $F$. subglutinans (FSUB), F. verticillioides (FVER), F. virguliforme (FVIR), F. armeniacum (FAR), F. avenaceum (FAVE), F. poae (FPO), and F. tricinctum (FTRI). 
solani, F. acuminatum, and $F$. graminearum were the species with the highest prevalence (recovered from the highest percentage of fields or counties) and the highest incidence (recovered from the greatest percentage of root pieces) in 2007 to 2009. Other species, such as $F$. armeniacum, $F$. avenaceum $F$. equiseti, $F$. poae, $F$. semitectum, $F$. subglutinans, $F$. tricinctum, and $F$. virguliforme, showed the lowest prevalence and incidence (Table 1). Mean incidence of $F$. oxysporum (14.9\%) did not differ significantly from $F$. acuminatum $(12.3 \%)$ and $F$. solani $(10.2 \%)$ but was greater than all other species. The same results were obtained for prevalence at the county level, with F. oxysporum (84.5\%), F. acuminatum (73.3\%), and $F$. solani $(73.0 \%)$ showing the higher prevalence compared with all other species. Due to greater variation among fields, differences in prevalence at the field level were not as significant $(P=0.003)$.

For the most frequent species identified in this study, such as $F$. oxysporum, $F$. solani, and $F$. acuminatum, prevalence was similar among years (Supplementary Figure 2); these species were recovered statewide in each year. For some species, such as F. graminearum, $F$. semitectum, and $F$. verticillioides, consistent patterns were evident in prevalence among year and geographically. For example, F. graminearum was present in all districts in 2007 but the fungus was not present in fields sampled from the East-Central, Southeast, and Northwest districts in 2008 or from the Southeast district in 2009. In contrast, prevalence patterns for $F$. semitectum and $F$. verticillioides were highly variable (Supplementary Figure 2). Species such as $F$. avenaceum, $F$. poae, and $F$. tricinctum, were found in only one field within one district. No significant differences in incidence were observed among different tillage practices or row spacing averaged over all Fusarium spp. or when analyzed for each species separately for (data not shown).

\section{Discussion}

This study provides the first documentation regarding frequency, prevalence, and geographic distribution of Fusarium spp. associated with soybean roots among the nine Iowa crop districts. Overall, $F$. acuminatum, $F$. graminearum, $F$. oxysporum, and $F$. solani were omnipresent and abundant in all nine Iowa crop districts, whereas $F$. armeniacum, $F$. avenaceum, $F$. equiseti, $F$. sporotrichioides, $F$. poae, $F$. proliferatum $F$. semitectum, $F$. subglutinans, $F$. tricinctum, $F$. verticillioides, and $F$. virguliforme were less frequently found. These observations would indicate that diversity of species associated with soybean roots in Iowa is higher than previously recognized by Nyvall (30), who found four species of Fusarium (F. oxysporum, F. solani, F. trincinctum, and F. roseum) colonizing soybean roots, stems, and pods.
F. oxysporum was the most common species and also the species showing the most morphological variability in this study. The high frequency of isolation of $F$. oxysporum found is consistent with work by Nyvall (30) and French and Kennedy (14), who both found that $F$. oxysporum was the most common Fusarium sp. isolated from soybean roots in Iowa and Minnesota, respectively. $F$. oxysporum and $F$. solani are well known as major causal agents of soybean root rot $(13,14,22,28,30)$ but there is limited information about pathogenicity of the other Fusarium spp. isolated from soybean roots. For most species, there is also scarce information about their epidemiology and impact of soybean yield. A recent study (9) compared the aggressiveness and yield impact of nine of the Fusarium spp. isolated from soybean roots in the Iowa survey reported here. In that study, at least some isolates of each of the nine species tested were found to be pathogenic on soybean. Further work is needed to better understand the role of Fusarium spp. as causal agents of seedling and root rot, as well as their epidemiology and yield impact in other soybean-producing regions.

It is generally accepted that $F$. oxysporum and $F$. solani $(25)$ are species complexes, showing a high level of variation within each group. In the study by Diaz et al. (9), variation in aggressiveness was found among and within Fusarium spp., particularly within $F$. solani and $F$. oxysporum. Additional work is needed to understand the genotypic and phenotypic diversity of these fungi on soybean and other crops. Some efforts are underway, and this has led to the recognition of $F$. commune K. Skovg., O'Donnell \& Nirenberg as a pathogenic component of the $F$. oxysporum complex on Iowa soybean (11). In the current study, however, $F$. commune is included in the $F$. oxysporum data. This work also led to new records of two other Fusarium spp. causing soybean root rot, F. armeniacum (12) (formerly described as $F$. acuminatum subsp. armeniacum) and $F$. proliferatum (10).

Although most of the species identified in our survey have been reported on soybean previously, often as seedling pathogens $(7,9,12,17,18,22,30,33)$, some species have not been associated with soybean roots at both vegetative (V2 to V5) and reproductive plant stages (R1 to R3), including $F$. avenaceum, $F$. poae, $F$. semitectum, $F$. sporotrichioides, $F$. subglutinans, and $F$. tricinctum. In this study, $F$. acuminatum, $F$. graminearum, $F$. oxysporum, and $F$. solani differed in frequency of isolation depending on plant stage. For example, $F$. oxysporum was more frequently isolated in early stages of the crop, supporting studies that have associated $F$. oxysporum with seedling diseases in soybean $(13,14,17,21,22)$. In contrast, $F$. solani was more frequently observed at reproductive stages than at vegetative stages, suggesting that $F$. solani colonization of roots may increase with plant growth. Other species did not differ

Table 1. Incidence (\%) and prevalence (\%) by field and county of Fusarium species recovered from soybean roots in 2007, 2008, and 2009

\begin{tabular}{|c|c|c|c|c|c|c|c|c|c|}
\hline \multirow[b]{3}{*}{ Fusarium spp. } & \multirow[b]{3}{*}{$\mathbf{I}^{\mathbf{b}}$} & \multicolumn{2}{|l|}{2007} & \multicolumn{3}{|c|}{2008} & \multicolumn{3}{|c|}{2009} \\
\hline & & \multicolumn{2}{|c|}{$\mathbf{P a}^{\mathbf{a}}$} & \multirow[b]{2}{*}{ I } & \multicolumn{2}{|c|}{$\mathbf{P}$} & \multirow[b]{2}{*}{$\mathbf{I}$} & \multicolumn{2}{|c|}{$\mathbf{P}$} \\
\hline & & County & Field & & County & Field & & County & Field \\
\hline F. acuminatum & 19.1 & 84.0 & 17.9 & 12.9 & 70.0 & 70.0 & 4.8 & 65.0 & 51.2 \\
\hline F. armeniacum & 0.0 & 0.0 & 0.0 & 1.5 & 12.5 & 12.5 & 0.3 & 7.5 & 7.0 \\
\hline F. avenaceum & 0.0 & 0.0 & 0.0 & 0.0 & 0.0 & 0.0 & 0.1 & 2.5 & 2.3 \\
\hline F. equiseti & 1.0 & 14.0 & 12.5 & 1.0 & 12.5 & 12.5 & 0.1 & 2.5 & 2.3 \\
\hline F. graminearum & 8.6 & 62.0 & 50.0 & 2.1 & 22.5 & 22.5 & 1.9 & 37.5 & 35.0 \\
\hline$F$. oxysporum & 20.3 & 86.0 & 12.5 & 14.1 & 80.0 & 80.0 & 10.3 & 87.5 & 81.4 \\
\hline F. poae & 0.0 & 0.0 & 0.0 & 0.0 & 0.0 & 0.0 & 0.1 & 2.5 & 2.3 \\
\hline F. proliferatum & 2.4 & 34.0 & 32.1 & 2.1 & 32.5 & 32.5 & 0.2 & 2.5 & 2.3 \\
\hline F. semitectum & 1.2 & 18.0 & 19.6 & 0.6 & 10.0 & 10.0 & 0.2 & 5.0 & 4.7 \\
\hline F. solani & 15.5 & 80.0 & 19.6 & 8.0 & 62.5 & 62.5 & 7.0 & 77.5 & 74.4 \\
\hline F. sporotrichioides & 2.2 & 28.0 & 26.8 & 2.3 & 20.0 & 20.0 & 0.6 & 15.0 & 14.0 \\
\hline F. subglutinans & 1.0 & 18.0 & 14.3 & 0.3 & 5.0 & 5.0 & 0.3 & 7.5 & 7.0 \\
\hline F. tricinctum & 0.0 & 0.0 & 0.0 & 0.0 & 0.0 & 0.0 & 0.1 & 2.5 & 2.3 \\
\hline F. verticillioides & 0.6 & 10.0 & 8.9 & 0.0 & 0.0 & 0.0 & 0.6 & 10.0 & 9.3 \\
\hline F. virguliforme & 0.4 & 4.0 & 3.6 & 0.0 & 0.0 & 0.0 & 0.2 & 5.0 & 4.7 \\
\hline
\end{tabular}

${ }^{\text {a }} \mathrm{P}=$ Prevalence (\%): $100 \times$ (total number of fields or counties in which each Fusarium species was present/total number of fields or counties sampled).

${ }^{\mathrm{b}} \mathrm{I}=$ Incidence $(\%)$ : $100 \times[$ (number of root pieces yielding a species/number of root pieces selected for identification) $\times($ number of root pieces yielding any isolate)]/total number of root pieces assessed. 
in frequency of isolation depending of plant growth stage. These results could lead to new research to describe trends in soybean root colonization in relation to plant development or growth stages.

In our study, the frequency of isolation of species of Fusarium varied substantially geographically and among years. Possible reasons for these patterns include differences in climate and topography, sampling error, crop management practices, and environmental conditions possibly related to soil types. In addition, the complexity of the soil microbial community may have played a role in the results obtained. In this survey, $23 \%$ of the total isolates obtained from soybean roots plated into semiselective medium were not Fusarium spp. Although we did not identify these other isolates, this illustrates the potential for diverse communities of root-associated microorganisms to influence colonization by Fusarium spp., thereby affecting our ability to detect tillage or geographical differences.

Several studies on distribution of Fusarium spp. around the world suggest that climate is a major factor determining the distribution of these fungi in soil $(6,35,36)$. Although the precise combinations of environmental conditions favoring Fusarium root rot on soybean are not known, it has been reported that the disease is more severe under cool, wet weather conditions $(28,30)$. During our study, average state temperatures from May to July 2007 were 18.3 to $23.3^{\circ} \mathrm{C}$ and precipitation was 78.2 to $131.1 \mathrm{~mm}$. For the 2008 season, temperature and precipitation were 14.4 to $23.3^{\circ} \mathrm{C}$ and 139.7 to $211.3 \mathrm{~mm}$, respectively. In contrast, average state temperatures for 2009 from May to August were 15.6 to $21.1^{\circ} \mathrm{C}$ and precipitation was 89.7 to $133.8 \mathrm{~mm}$. The cool and wet weather pattern in 2008 might have favored development of damping-off by Fusarium spp. early in the season that could cause plant mortality in Iowa soybean fields. Also, the high precipitation and flooding conditions in summer 2008 may have favored disease development and increased incidence and prevalence of the most frequent species, such as $F$. acuminatum, $F$. graminearum, $F$. oxysporum, and $F$. solani (Table 1). Similarly, cool temperatures during summer 2009 may have influenced the abundance and frequency of isolation of some Fusarium spp.

In our study, no differences were found in Fusarium sp. composition and frequency of isolation among tillage practices and among different row spacing. Reports on the effects of tillage practices on Fusarium populations are contradictory; tillage has been reported to increase $(8,38)$, decrease, or have no effect on Fusarium populations (39). Further research might be needed to determine whether there is an effect of tillage practices and row spacing on Fusarium root rot species on soybean and to better understand if root rot disease in soybean could increase under these management practices in Iowa fields.

Using morphological characterization in combination with molecular analysis, we documented 15 Fusarium spp. associated with soybean roots at two soybean growth stages. Our results confirm that, in Iowa soils, the Fusarium root rot complex is diverse, as previously recognized $(9,28,30)$. The new information generated in this study on the diversity and frequency of Fusarium spp. associated with soybean roots suggests the need to understand the importance of root-infecting Fusarium spp. on soybean productivity in Iowa and test the effectiveness of some management tools, such as seed treatments, to control this pathogen complex.

\section{Acknowledgments}

This project was funded by the Iowa Soybean Association and United States Department of Agriculture North Central Integrated Pest Management grant program. We thank M. Beattie, M. Agudelo, A. Thompson, J. P. Soto-Arias, S. Chalfant, C. Marett, and M. Ellis for their technical assistance and cooperation in this study; G. Tylka and S. Cianzio for providing helpful suggestions for revising the manuscript; and Iowa State University Extension Field Agronomists J. DeJong, P. Kassel, B. Lang, M. Licht, M. Wuebker, J. Holmes, A. Saeugling, J. Fawcett, V. Schmitt, K. Jensen, and M. Carlton for their cooperation in sampling soybean plants around Iowa.

\section{Literature Cited}

1. Aoki, T., O'Donnell, K., Homma, Y., and Lattanzi, A. R. 2003. Sudden death syndrome of soybean is caused by two morphologically and phyloge- netically distinct species within the Fusarium solani species complex-F virguliforme in North America and F. tucumaniae in South America. Mycologia 95:660-684

2. Armstrong, G. M., and Armstrong, J. K. 1950. Biological races of the Fusarium causing wilt of cowpeas and soybeans. Phytopathology 40:181193.

3. Baili, Y., Zhang, Q., Li Bing, D., and Guo, Q. Y. 2009. Identification and pathogenicity determination of the pathogenic Fusarium of soybean root rot in the Altay region of Xinjiang. Xinjiang Agric. Sci. 46:543-548.

4. Bienapfl, J. C. 2011. Fusarium and Phytophthora species associated with root rot of soybean (Glycines max). Ph.D. thesis. University of Minnesota, St. Paul.

5. Bienapfl, J. C., Malvick, D. K., and Percich, J. A. 2010. First report of Fusarium redolens causing root rot of soybean in Minnesota. Plant Dis. 94:1069.

6. Boohan, F. M., Brennan, J., and Cooke, B. M. 2003. Influence of climatic factors on Fusarium species pathogenic to cereals. Eur. J. Plant Pathol. 109:755-768.

7. Broders, K. D., Lipps, P. E., Paul, P. A., and Dorrance, A. E. 2007. Evaluation of Fusarium graminearum associated with corn and soybean seed and seedling disease in Ohio. Plant Dis. 91:1155-1160.

8. Carroll, R. B., and Leath, S. 1983. Effect of tillage practices on Fusarium blight of soybean. (Abstr.) Phytopathology 73:811.

9. Díaz Arias, M. M., Leandro, L. F., and. Munkvold, G.P. 2013. Aggressiveness of Fusarium Species and Impact of Root Infection on Growth and Yield of Soybeans. Phytopathology. Online publication. http://apsjournals. apsnet.org/doi/pdf/10.1094/PHYTO-08-12-0207-R

10. Diaz Ariaz, M. M., Munkvold, G. P., and Leandro, L. F. 2011. First report of Fusarium proliferatum causing root rot in soybean (Glycine max) in Iowa. Plant Dis. 95:1316.

11. Ellis, M. L., Díaz Arias, M. M., Cruz Jiménez, D. R., Munkvold, G. P., and Leandro, L. F. 2012. First report of Fusarium commune causing dampingoff, seed rot, and seedling root rot on soybean (Glycine max) in the United States. Plant Dis. 97:284.

12. Ellis, M. L., Díaz Arias, M. M., Leandro, L. F., and Munkvold, G. P. 2012 First report of Fusarium armeniacum causing seed rot and root rot on soybean (Glycine max) in the United States. Plant Dis. 96:1693.

13. Farias, G. M., and Griffin, G. J. 1989. Roles of Fusarium oxysporum and Fusarium solani in Essex disease of soybean in Virginia. Plant Dis. 73:3842.

14. French, E. R., and Kennedy, B. W. 1963. The role of Fusarium in the root rot complex on soybean in Minnesota. Plant Dis. Rep. 47:672-676.

15. Geiser, D. M., Jimenez-Gasco, M. M., Kang, S., Makalowska, I., Veeraraghavan, N., Ward, T. J., Zhang, N., Kuldau, G. A., and O’Donnell, K. 2004. FUSARIUM-ID v. 1.0: A DNA sequence database for identifying Fusarium. Eur. J. Plant Pathol. 110:473-479.

16. Gongora, C., and. Leandro, L. 2011. Plant age affects root infection and development of foliar symptoms of soybean sudden death syndrome. Plant Dis. 95:242-247.

17. Grant, C. E., Phipps, P. M., and Roane, C. W. 1981. Etiology of a dampingoff disease of soybeans in Virginia. (Abstr.) Phytopathology 71:767.

18. Hartman, G. L., Sinclair, J. B., and Rupe, J. C. 1999. Compendium of Soybean Diseases, 4th ed. American Phytopathological Society, St. Paul, MN.

19. Innis, M. A., Gelfand, D. H., Sninsky, J. J., and White, T. J., 1990. PCR Protocols: A Guide to Methods and Applications. Academic Press Inc., New York.

20. Jasnic, S. M., Vidic, M. B., Bagi, F. F., and Dordevic, V. W. 2005. Pathogenicity of Fusarium species in soybean. Proc. Nat. Sci. Matica Srska Novi Sad 109:113-212.

21. Kikic, O., and Griffin, G. J. 1998. Effect of dsRNA-containing and dsRNAfree hypovirulent isolates of Fusarium oxysporum on severity of Fusarium seedling disease of soybean in naturally infested soil. Plant Soil 201:125-135.

22. Killebrew, J. F., Roy, K. W., and Abney, T. S. 1993. Fusaria and other fungi on soybean seedlings and roots of older plants and interrelationships among fungi, symptoms, and soil characteristics. Can. J. Plant Pathol. 15:139-146.

23. Koning, G., Hamman, B., Eicker, A., and van de Venter, H. A. 1995. First report of Fusarium equiseti on South African soybean cultivars. Plant Dis. 79:754.

24. Leslie, J. F., Pearson, C. A., Nelson, P. E., and Toussoun, T. A. 1990. Fusarium spp. from corn, sorghum, and soybean fields in the central and eastern United States. Phytopathology 80:343-350.

25. Leslie, J. F., and Summerell, B. A. 2006. The Fusarium Laboratory Manual. Blackwell Publishing, Oxford

26. Maloy, O. C., and Murray, T. D. 2001. Pages 312-328 in: Encyclopedia of Plant Pathology, Vol. 2 Set. John Wiley \& Sons, Inc., New York.

27. Navi, S. S and Yang, X. B. 2008. Foliar symptom expression in association with early infection and xylem colonization by Fusarium virguliforme (formerly $F$. solani $\mathrm{f}$. sp. glycines), the causal agent of soybean sudden death syndrome. Plant Health Progress. Online publication. doi:10.1094/PHP2008-0222-01-Rs

28. Nelson, B. D. 1999. Fusarium blight or wilt, root rot, and pod and collar rot. Pages 35-36 in: Compendium of Soybean Diseases, 3rd ed. American Phytopathological Society, St. Paul, MN. 
29. Nelson, B. D., Hansen, J. M., Windels, C. E., and Helms, T. C. 1997. Reaction of soybean cultivars to isolates of Fusarium solani from Red River valley. Plant Dis. 81:664-668.

30. Nyvall, R. F. 1976. Colonization of soybeans by species of Fusarium. Mycologia 68:1002-1010.

31. O’Donnell, K., Kistler, H. C., Cigelnik, E., Ploetz, R. C. 1998. Multiple evolutionary origins of the fungus causing Panama disease of banana: Concordant evidence from nuclear and mitochondrial gene genealogies. Proc. Natl. Acad. Sci. USA 95:2044-2049.

32. Pioli, R. N., Mozzoni, L., and Morandi, E. N. 2004. First report of pathogenic association between Fusarium graminearum and soybean. Plant Dis. 2004, 88:220.

33. Rizvi, S. S. A., and Yang, X. B. 1996. Fungi associated with soybean seedling disease in Iowa. Plant Dis. 80:57-60.

34. Rodríguez, A. A. C., and Meneses, M. 2005. Identification and pathogenic characterization of endophytic Fusarium species from cowpea seeds. Mycopathologia 159:79-85.

35. Sanglang, A. E., Burgess, L. W., Backhouse, D., Duff, J., and Wurst, M.
1995. Mycogeography of Fusarium species in soils from tropical, arid and Mediterranean regions of Australia. Mycol. Res. 99:523-528.

36. Saremi, H., Burgess, L. W., and Backhouse, D. 1998. Temperature effects on relative abundance of Fusarium species in a model plant-soil ecosystem. Soil Biol. Biochem. 31:941-947.

37. Schlub, R. L, Lockwood, J. L., and Komada, H. 1981. Colonization of soybean seeds and plant tissue by Fusarium species in soil. Phytopathology 71:693-696.

38. Steinkeller, S., and Langer, I. 2004. Impact of tillage on the incidence of Fusarium spp. in soil. Plant Soil 267:13-22.

39. Swan, L. J., Backhouse, D., and Burges, L. W. 2000. Surface soil moisture and stubble management practice effects on the progress of infection of wheat by Fusarium pseudograminearum. Aust. J. Exp. Agric. 40:693-698.

40. Yang, X. B., and Feng, F. 2001. Ranges and diversity of soybean fungal diseases in North America. Phytopathology 91:769-775.

41. Zhang, J. X., Xue, A. G., Zhang, H. J., Nagasawa, A. E., and Tambong, J. T. 2010. Response of soybeans cultivars to root rot caused by Fusarium species. Can. J. Plant Sci. 90:767-776. 